\title{
Value of CD15 immunostaining in diagnosing Hodgkin's disease: a review of published literature
}

\author{
P A HALL, ${ }^{*} \dagger$ A J D'ARDENNE* \\ From the Department of ${ }^{*}$ Histopathology and $\dagger$ Imperial Cancer Research Fund Department of Medical \\ Oncology, St Bartholomew's Hospital, London
}

SUMMARY The role of antibodies of CD15 as diagnostic markers of Hodgkin's disease was assessed from a review of the literature. A total of 571 cases of Hodgkin's disease and 386 cases of nonHodgkin's lymphoma were included. The sensitivity of CD15 in detecting cases of Hodgkin's disease was $80 \%$ or $91 \%$ if cases of lymphocyte predominant Hodgkin's disease were excluded. The specificity of CD15 was only $80.6 \%$, or in other words, $19.4 \%$ of cases of non-Hodgkin's lymphoma were CD15 positive. In an ideal test both the sensitivity and specificity would be $100 \%$ and if the test performance were no better than chance then they would both be $50 \%$. It is concluded that CD 15 immunostaining cannot be regarded as a sensitive or specific marker of Hodgkin's disease. Application of this formal method of analysis to other immunohistological reagents and panels of antibodies is discussed.

The accurate diagnosis of lymphoid neoplasms has increased in importance in recent years, with improvements in treatment and prognosis. The protean histopathological appearances of Hodgkin's disease are well known ${ }^{12}$ yet several series have shown the difficulty that this diagnosis can pose to experienced pathologists. ${ }^{3-5}$ Cells resembling SternbergReed cells can be seen in reactive conditions and in a variety of lymphoid and non-lymphoid neoplasms. ${ }^{6-8}$ The application of immunohistological methods to lymphoid lesions has contributed to our understanding of these disorders and has provided an objective means of confirming tumour lineage. ${ }^{910}$ These methods have helped predominantly in the diagnosis of non-Hodgkin's lymphomas, although the immunological examination of cases of Hodgkin's disease has provided information regarding its complex cellular composition. ${ }^{11-13}$ Unfortunately, there has been less progress in the definition of phenotypic features that allow cases of Hodgkin's disease to be distinguished clearly from those of non-Hodgkin's lymphomas. This distinction is important, not just from the point of view of furthering our understanding of these diseases, but from the practical difference in their management.

The monoclonal antibody Leu Ml was raised against the U-937 histiocytic cell line ${ }^{14}$ and recognises a trisaccharide antigen lacto- $\mathrm{N}$-fucopentaose III or

Accepted for publication 11 May 1987 the so called " $\mathrm{X}$ hapten". ${ }^{15}$ Other antibodies that recognise this antigen are grouped or clustered in cluster of differentiation 15 (CD15). ${ }^{15} 16$ Several studies have described the reactivity of CD15 with Sternberg-Reed cells ${ }^{1718}$ and have raised the possibility that expression of CD15 could be used to discriminate between Hodgkin's disease and non-Hodgkin's lymphomas. More recently reports of non-Hodgkin's lymphomas staining with Leu M1 have cast doubt on its value as a disease marker. ${ }^{19-22}$

Our initial experience with Leu M1 (Becton Dickinson) was favourable and we found it highlighted Reed-Sternberg cells in polymorphic cellular infiltrates, often picking them out when they were sparse. We interpreted staining with this antibody as corroborating a diagnosis of Hodgkin's disease when that diagnosis was suspected on other grounds, but in an unselected series of 57 cases of high grade nonHodgkin's lymphoma we found six cases (three B cell, three T cell) that stained with Leu M1. It is in those cases where there is a differential diagnostic problem between high grade lymphoma and Hodgkin's disease that the need for an objective means of distinction is required; thus we decided to review the published literature.

In this review the evidence that CD15 antibodies can be used as markers of Hodgkin's disease is assessed by formal analysis of their immunohistological reactivity as described in the published reports. This review aims to illustrate the problems of 
translating published results into clinical practice and to highlight the dangers of using a single marker in pathological diagnosis. The analytical methods we used may be of potential value in the evaluation of other antibodies and thus provide the pathologist with an objective means of interpreting published immunohistological results. Although well known in other branches of laboratory medicine, the following analytical concepts are less widely used in histopathology.

\section{Analytical methods}

The evaluation of a test comprises two components. First, an assessment of the test's validity-that is, the extent to which a technique measures what it purports to study-and secondly, an assessment of its reproducibility. The reproducibility itself comprises two components: first, the technical reproducibility of the method; and secondly, the reproducibility of the interpretation of the immunostained section by the pathologist.

The methods used for the assessment of validity have been reviewed elsewhere. ${ }^{23-26}$ Any new test should be compared with a reference test or "gold standard" and the results of such a comparison placed in a $2 \times 2$ contingency table (table 1). From such data a series of parameters (operating characteristics) can be defined:

(i) Sensitivity $(a / a+c)$ or the number of cases with a true positive test result divided by the total number of positive cases as defined by the reference method.

(ii) Specificity $(d / b+d)$ or the number of cases with a false positive test result divided by the total number of cases found to be negative with the reference test. (iii) The predictive value of a positive test $(a / a+b)$ is a measure of the probability that the target disorder is present given a positive result while the predictive value of a negative test $(d / c+d)$ is a measure of the probability that the target disorder is absent given a negative result.

(iv) Both these parameters depend on the prevalence of the disorder in the population examined $(a+c / N)$.

Table 1 Analysis of a test

\begin{tabular}{|c|c|c|c|}
\hline \multirow[b]{2}{*}{ New test } & \multicolumn{3}{|l|}{ Reference test } \\
\hline & Positive & Negative & \\
\hline Positive & True positive & $\begin{array}{l}\text { b } \\
\text { False positive }\end{array}$ & $a+b$ \\
\hline Negative & $\begin{array}{l}\text { c } \\
\text { False negative }\end{array}$ & $\stackrel{\mathrm{d}}{\text { True negative }}$ & $c+b$ \\
\hline & $a+c$ & $b+d$ & $\begin{array}{l}\mathbf{N}=a+b+ \\
c+d\end{array}$ \\
\hline
\end{tabular}

(v) The accuracy of a test $(a+d / N)$ is a measure of the similarity between the new test and the reference test in defining positive or negative cases. A highly discriminant or accurate test will distinguish two populations with very few false positive or negative results - that is, it will be both sensitive and specific.

(vi) The interpretation of a test result depends on the pretest probability of disease-that is, if a pretest probability is low a negative test result has little influence on the diagnosis while a positive test result has a large effect, or given a high pretest probability, a negative test result has a large influence and a positive test a small influence on the diagnosis. Lastly, the evaluation of the validity of a test is influenced by the spectrum of cases chosen for the population studied and bias can easily enter the analysis. ${ }^{27}$

In an ideal test there would be no false negative and false positive results and thus the sensitivity, specificity, accuracy and both positive and negative predictive values would be $100 \%$. If the test performance was not better than chance at discriminating positive and negative cases defined by the reference test, however, then all parameters of test validity would be $50 \% .^{23}$

The prevalence of a disorder in the population being examined is of particular importance. At a given prevalence a unit increase in the sensitivity of a test leads to a bigger increase in the predictive value of a negative result than a unit increase in the specificity. Conversely, at a given prevalence a unit increase in the specificity leads to a bigger increase in the predictive value of a positive result than a unit increase in the sensitivity. As the prevalence of a disorder increases in the population studied, then the efficiency (or accuracy) of the test will increase while the efficiency will fall if the reverse is the case. ${ }^{23}$ If the sample size $(\mathrm{N})$ is small then there will be a large error in the estimates of the operating characteristics. ${ }^{28}$

The final point to consider is that the operating characteristics of a test may well vary as the test is used. ${ }^{29}$ Why should this be so? Many factors are at play-for example, the population used to define the operating characteristics is probably different to that normally seen; there will be a greater range of individuals using the test with varying degrees of skill; and as the test is more widely used there will inevitably be an increasing number of exceptions and unusual cases that will affect the parameters. Thus it is important to be aware of the limitations of defining operating characteristics and to assess continually the usefulness of a given test.

\section{Review of published cases}

Nineteen reports ${ }^{17-22}$ 30-42 describing series of cases stained with Leu M1 (or an equivalent CD15 anti- 
Table 2 Cases of lymphoma stained with CD15 grouped by histological subtype

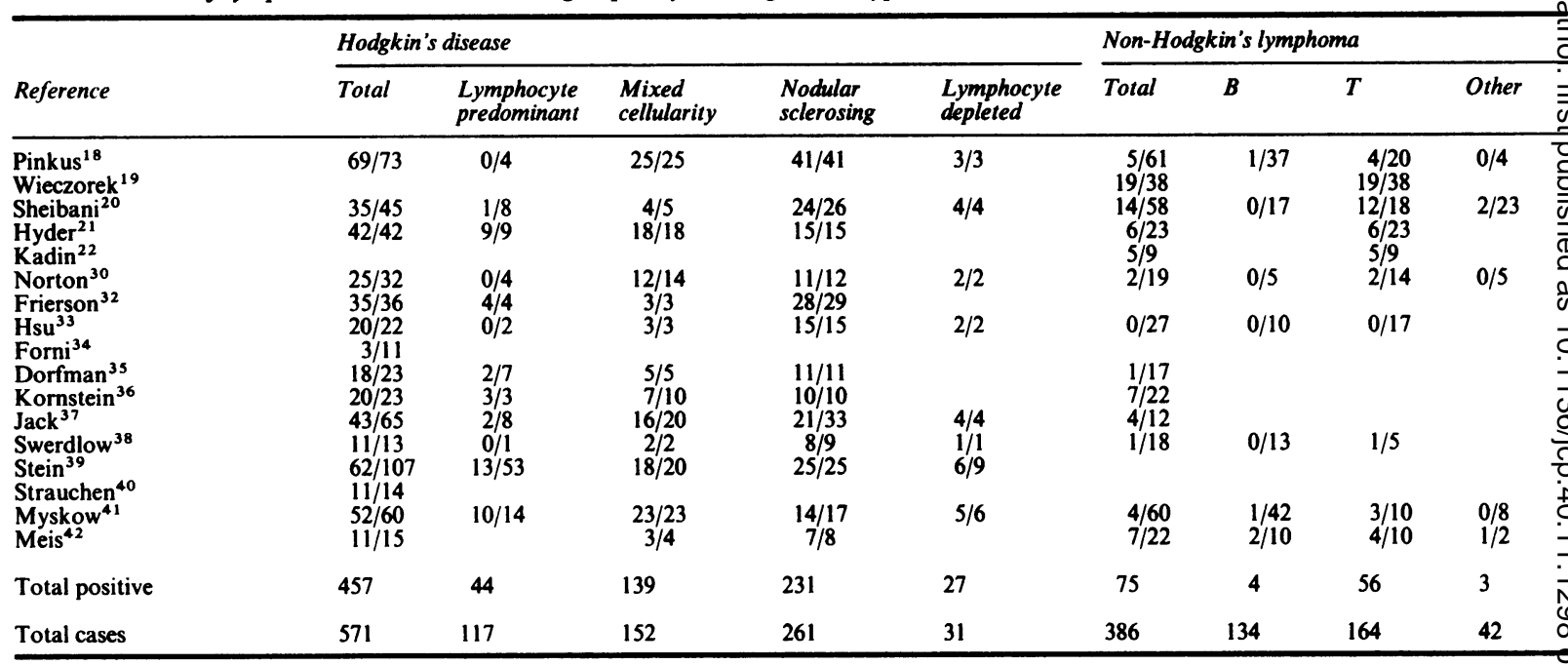

body) were scrutinised. Single case reports were not considered and those reports duplicating cases previously reported were, as far as possible, excluded. The manner of case selection, the nature of the staining pattern, and where possible, the proportion of cells staining were recorded.

Seventeen of the series were evaluable and table 2 shows the result. In some series a detailed breakdown of the subtypes of lymphoma was not given. From these data contingency tables showing all cases (table 3 ) and all cases excluding lymphocyte predominant Hodgkin's disease (table 4) were constructed. Table 5 gives the calculated parameters of validity.

The proportion of Reed-Sternberg cells staining with CD15 varied greatly between cases in all series. In general, the pattern of staining was similar in all cases of Hodgkin's disease and in those cases of nonHodgkin's lymphoma that stained-that is, membrane staining with Golgi or globular cytoplasmic staining. Some workers, however, suggested that

Table 3 Analysis of a CD15 staining (new test) compared with pathologists' diagnosis (reference test) from pooled data derived from table 2

\begin{tabular}{llll}
\hline \multirow{4}{*}{ New test: CD15 } & \multicolumn{3}{l}{ Reference test: pathologist } \\
\cline { 2 - 4 } & Positive & Negative & \\
\hline Positive & $\mathrm{a}$ & $\mathrm{b}$ & $\mathrm{a}+\mathrm{b}$ \\
& 457 & 75 & 532 \\
Negative & $\mathrm{c}$ & $\mathrm{d}$ & $\mathrm{c}+\mathrm{d}$ \\
& 114 & 311 & 425 \\
& $\mathrm{a}+\mathrm{c}$ & $\mathrm{b}+\mathrm{d}$ & $\mathrm{a}+\mathrm{b}+\mathrm{c}+\mathrm{d}$ \\
& 571 & 386 & 957 \\
\hline
\end{tabular}

cases of non-Hodgkin's lymphoma staining with CD15 do so in a granular manner and can thus be distinguished from Hodgkin's disease, ${ }^{18303643}$ although others have not confirmed this. ${ }^{21}$ While the effect of fixation was variable, staining of B5 fixed material being consistently stronger than that of formalin fixed material, the results obtained were similar. Crocker and Burnett ${ }^{16}$ suggested that the differences in fixation were significant and may thus explain some of the apparent discrepancies between series.

In many series a detailed breakdown of the subtypes of lymphoma was given. From these data contingency tables showing all cases (table 3) and all cases excluding lymphocyte predominant Hodgkin's disease (table 4) were constructed. The calculated operating characteristics are shown in table 5 . It is clear from the results of this analysis that CD15 immunostaining used on its own is neither a specific nor sensitive marker of Hodgkin's disease.

Table 4 Analysis of CD15 staining compared with reference test with all cases of lymphocyte predominant Hodgkin's disease censored from data derived from table 1

\begin{tabular}{llll}
\hline & \multicolumn{4}{l}{ Reference test: pathologist } \\
\cline { 2 - 4 } New test: CD15 & Positive & Negative & \\
\hline Positive & $\mathrm{a}$ & $\mathrm{b}$ & $\mathrm{a}+\mathrm{b}$ \\
& 413 & 75 & 488 \\
Negative & $\mathrm{c}$ & $\mathrm{d}$ & $\mathrm{c}+\mathrm{d}$ \\
& 41 & 311 & 352 \\
& $\mathrm{a}+\mathrm{c}$ & $\mathrm{b}+\mathrm{d}$ & $\mathrm{a}+\mathrm{b}+\mathrm{c}+\mathrm{d}$ \\
& 454 & 386 & 840 \\
\hline
\end{tabular}


Table 5 Results of CD15 analysis from pooled data expressed as percentages

\begin{tabular}{|c|c|c|}
\hline & $\begin{array}{l}\text { All cases } \\
\text { of Hodgkin's } \\
\text { disease }\end{array}$ & $\begin{array}{l}\text { Lymphocyte predominant } \\
\text { Hodgkin's disease excluded }\end{array}$ \\
\hline \multirow{3}{*}{$\begin{array}{l}\text { Sensitivity }(a / a+c) \\
\text { Specificity }(d / b+d) \\
\text { Accuracy }(a+d / N) \\
\text { Predictive value of } a \\
\text { positive result }(a / a+b) \\
\text { Predictive value of } a \\
\text { negative result }(d / c+d)\end{array}$} & $\begin{array}{l}80 \cdot 0 \\
80 \cdot 6 \\
80 \cdot 2\end{array}$ & $\begin{array}{l}90 \cdot 9 \\
80 \cdot 6 \\
86 \cdot 2\end{array}$ \\
\hline & 85.9 & $84 \cdot 6$ \\
\hline & $73 \cdot 2$ & $88 \cdot 3$ \\
\hline
\end{tabular}

\section{Is this a fair analysis?}

The first major problem of this form of analysis is that the reference test or "gold standard" used is the subjective interpretation of the pathologists concerned. These differ in each series. Studies are often retrospective, cases are selected in different ways, and the manner of case selection is rarely stated. Most of the cases detailed in the CD15 review were probably selected as characteristic morphological examples of lymphoma. Relatively few cases were acknowledged as being difficult diagnostic problems. Furthermore, the prevalence of Hodgkin's disease and nonHodgkin's lymphoma in the individual or combined series is unlikely to reflect that seen in the course of diagnostic histopathology.

Another important and related problem is whether it is valid to attempt to identify a disease on the basis of expression of a single antigen, especially when the underlying nature of the disease remains unknown, as in Hodgkin's disease. There are precedents for the use of a single marker for the definition of pathological subgroups of disease: the common acute lymphoblastic leukaemia antigen (CALLA or CD10) defines a clinically important subgroup of acute lymphoblastic leukaemia ${ }^{44}$ and the presence of immunoreactivity with the antibody Kil (CD30) may define a subgroup of large cell non-Hodgkin's lymphoma. ${ }^{45}$ With both these antibodies exceptions exist; "aberrant" expression by other tumours occurs in CALLA ${ }^{910}$; and $\mathrm{Kil}$ recognises determinants on Reed-Sternberg cells ${ }^{13}$ and is by no means lineage specific. $^{45}$

In the light of the known diagnostic difficulty that Hodgkin's disease often poses, might it be preferable to use the expression of an antigen such as CD15 as the main criterion for diagnosis? It could be argued that this would lead to improved inter- and intraobserver reproducibility but there is no objective evidence to support this at present. Given our poor understanding of the biology of CD15 expression and its relation to lymphoma, the use of CD15 to define Hodgkin's disease seems to be premature. Indeed, Jack et $a l^{37}$ stated that due to its insensitivity (high false negative rate in their series), "Leu M1 positivity should not become a prerequisite for the diagnosis of Hodgkin's disease".

The false positive results with CD15 in nonHodgkin's lymphomas, particularly peripheral $\mathrm{T}$ cell lymphoma, may, in fact, reflect a similarity in their biology. The initial report of MMA (Leu M1) by Hanjan et al showed that the antigen recognised was present on activated $\mathrm{T}$ cells. ${ }^{14}$ It may be that CD15 expression is a feature of lymphocyte activation ${ }^{45}$ and thus can occur in Hodgkin's disease as well as B and (more commonly) T cell lymphomas. Conversely, some of the false negative results are in the lymphocyte predominant form of Hodgkin's disease. The lymphocyte predominant form of Hodgkin's disease has a substantially lower incidence of CD15 expression in several ${ }^{21323641}$ but not all ${ }^{17183539}$ series. This is particularly so if the nodular form of the disease is considered. Some workers have used this as further evidence for suggesting that nodular, lymphocyte predominant Hodgkin's disease is a distinct pathological entity. While this may be so, removal of lymphocyte predominant Hodgkin's disease from the analysis does not greatly improve the operating characteristics of the test (table 5).

A further difficulty with CD15 and the diagnosis of Hodgkin's disease is that not only is the disease ill defined, the clinical importance of the antigen recognised by CD15 is also ill defined. Several studies $^{203846}$ have shown that CD15 immunoreactivity is found in a wide range of normal tissues and non-lymphoid neoplasms. This may reflect cross reactivity with related epitopes or expression of the same epitope in a variety of tissues. Whatever the explanation, it illustrates that several aspects of antibody reactivity need to be considered-namely, hapten/molecular specificity; cell/tissue specificity; and disease specificity. Although these are related they are not necessarily identical.

Although the analytical methods that we have used have drawbacks, we feel that the general conclusions are valid. Furthermore, this form of analysis may help put the literature into a perspective from which more rational decisions regarding the utility of immunohistochemical reagents in diagnostic pathology may be made.

\section{Reproducibility of CD15 immunostaining}

Another aspect of evaluation of a test relates to its technical reproducibility. Little information is available regarding the interdepartmental reproducibility of immunohistology, although one small study of anti-immunoglobulin staining of the same case by different departments indicated good concordance. ${ }^{47}$ We found that a wide range of different methods had 
been used and this may have accounted for some differences. A wide range of monoclonal antibodies are now available, often from more than one source (for example, several CD15 reagents are available; Leu M1 Becton Dickinson; Dako M1 Dakopatts; Tu9 Clonab/Biotest Diagnostics; numerous "private" antibodies), and little data are available on their comparability for use in diagnostic pathology. ${ }^{35} \mathrm{~A}$ system of comparison similar to that suggested for virological reagents might be of value. ${ }^{48}$

The difficulties of interpreting the patterns of immunostaining seen with CD15 and other antibodies have been reported previously. It may be that there are differences in staining pattern in Hodgkin's disease and non-Hodgkin's lymphoma, but the published reports offer no definitive explanations on this point. Suffice to say that this is an aspect of immunohistochemistry that requires great care.

\section{The value of panels of reagents}

In general, panels of antibodies are considered to be preferable to the use of a single reagent. The use of CD15 antibody together with other reagents may increase its diagnostic accuracy. ${ }^{43}$ It may be that in the correct morphological setting the expression of CD15 and the absence of detectable leucocyte common antigen (CD45) is a characteristic phenotype of Hodgkin's disease ${ }^{354243}$ but not all have found this to be so. ${ }^{3341}$ Unfortunately, there are not yet sufficient published data to assess critically this possibility.

The application of panels of antibodies has been extensively investigated in tumour diagnosis, ${ }^{49-51}$ in neuropathology, ${ }^{52}$ and in the analysis of lymphoid and haematological neoplasia. ${ }^{9-1153}$ The combination of tests, as in the use of panels of antibodies, can be analysed considering their operating characteristics ${ }^{23-26}$ by "discriminant analysis". This is not without potential problems. Tests may be arranged in parallel (either or both must be positive) or in series (both must be positive) to define some disease as present. In the former combination of tests the sensitivity is increased but with reduced specificity; in the latter the specificity is increased with reduced sensitivity. To summarise Griner $^{24}$; if all tests in a panel are positive or all are negative the panel is helpful, excluding or confirming disease. If one is positive and others are negative (say) then this may lead to confusion. When dealing with immunohistochemistry, the negative result is often a problem, particularly if diagnoses are to be made by the absence of a marker(s). To quote Sloane and Ormerod: "negative results are of course unhelpful". 54

\section{Is the method of analysis generally applicable?}

Leader et al recently incorporated assessment of sensitivity and specificity in publications on immunohistochemistry. ${ }^{556} \mathrm{~A}$ discussion of the value of carcinoembryonic antigen (CEA) immunostaining and periodic acid Schiff histochemistry (PAS-D) after diastase treatment in the differential diagnosis of mesothelioma from adenocarcinoma in similar terms has recently been reported..$^{57}$ Another study showed that while immunostaining with CEA was of some value in the distinction of adenocarcinoma (CEA positive) from mesothelioma (CEA negative), both false positive and false negative results occurred. ${ }^{58}$ It should be noted that the numbers in some of these series are relatively small and that small sample size leads to poor estimates of probability in this form of analysis. ${ }^{28}$ The formal analysis might usefully be applied to other antibodies such as prostate specific antigen-prostatic acid phosphatase, for example. Similar methods may be applied in other areas of histopathology: Minkowitz et al applied them to the assessment of the diagnostic value of "Tru-Cut" needle biopsy of the breast. ${ }^{59}$

\section{Conclusions}

Immunohistology is a useful adjunct to conventional methods of histological diagnosis but it cannot be interpreted in isolation. The value of the technique varies considerably with the diagnostic problem and the reagents used. Warnke and Rouse reported an assessment of the limitations and pitfalls in the application of immunohistology in their haematopathology practice. ${ }^{60}$ They emphasised that the published reports on CD15 staining in Hodgkin's disease was largely based "on typical cases .... and the findings may not be relevant to staining in difficult problem cases". In their reported experience they found that CD15 immunostaining was helpful in only 17 of 36 cases of Hodgkin's disease seen in one year. As our need for objective help from immunohistochemistry is most apparent in "the difficult case"-for example, in the distinction of T cell lymphoma from Hodgkin's disease-and because $T$ cell tumours not uncommonly express CD15, it is clear that CD15 antibodies are of little value in this diagnostic dilemma. Although CD15 immunostaining may provide further information relating to the phenotypic feature of lymphoma in general and Hodgkin's disease in particular, on the basis of the published reports, it cannot on its own be regarded as a diagnostic discriminant of Hodgkin's disease.

Analysis of published data in the way outlined in this review may supplement casual reading of the literature and personal experience. Data derived from 
this method might possibly be applied to increase the objectivity of histopathological and immunohistochemical decision making. Indeed, data produced in this manner could be of value in developing the use of Bayes' theorem and formal decision analysis in histopathology. ${ }^{61}$

We thank Drs Paul Grint, Adrienne Flanagan, AG Stansfeld and Professor G Slavin for helpful discussion. PAH is an ICRF Research Fellow and AJdA is supported in part by the ICRF.

\section{References}

1 Stansfeld AG. Lymph node biopsy interpretation. London: Churchill Livingstone, 1985.

2 Wright DH, Isaacson PG. Biopsy pathology of the lymphoreticular system. London: Chapman and Hall, 1983.

3 Symmers WStC. Survey of the eventual diagnosis in 600 cases referred for a second opinion after an initial diagnosis of Hodgkin's disease. J Clin Pathol 1968;21:650-3.

4 Coppleson LW, Factor RM, Strum SB, Graff PW, Rappaport H. Observer disagreement in the classification and histology of Hodgkin's disease. JNCI 1970;45:731-40.

5 Miller TP, Byrne GE, Jones SE. Mistaken clinical and pathological diagnoses of Hodgkin's disease: a southwest oncology group study. Cancer Treat Rep 1982;66:645-51.

6 Tindle BH, Parker JW, Lukes RJ. "Reed Sternberg Cells" in infectious mononucleosis. Am J Clin Pathol 1972;58:607-17.

7 Strum SB, Park JK, Rappaport H. Observation of cells resembling Reed Sternberg cells in conditions other than Hodgkin's disease. Cancer 1970;26:176-90.

8 Dorfman RF, Warnke R. Lymphadenopathy simulating malignant lymphomas. Hum Pathol 1974;5:519-50.

9 Stein H, Lennert K, Feller AC, Mason DY. Immunohistological analysis of human lymphoma: correlation of histological and immunological categories. Adv Cancer Res 1984;47:67-146.

10 Foon KA, Todd RF. Immunological classification of leukaemia and lymphoma. Blood 1986;68:1-31.

11 Abdulaziz Z, Mason DY, Stein H, Gatter KC, Nash JRG. An immunohistological study of the cellular constituents of Hodgkin's disease using a panel of monoclonal antibodies. Histopathology 1984;8:1-27.

12 Dorreen MS, Habeshaw JA, Stansfeld AG, Wrigley PFM, Lister TA. Characteristics of Sternberg Reed cells and related cells in Hodgkin's disease: an immunohistological study. $\mathrm{Br} \mathrm{J}$ Cancer 1984;49:465-76.

13 Stein H, Gerdes J, Schwab U, et al. Evidence for the detection of the normal counterpart of Hodgkin and Reed-Sternberg cells. Haematol Oncol 1983;1:21-9.

14 Hanjan SNS, Kearney JF, Cooper MD. A monoclonal antibody (MMA) that identifies a differentiation antigen on human myelomonocytic cells. Clin Immunol Immunopathol 1982;23: 172-88.

15 Bernstein ID, Self S. Joint report of the myeloid section of the 2nd international workshop on leucocyte differentiation antigens. In: Reinherz EL, Haynes BF, Nadler LM, Bernstein ID, eds. Leucocyte typing II. Berlin: Springer Verlag, 1986:1-25.

16 Crocker J, Burnett D. Granulocyte markers in histopathology: a review. J Pathol 1986;150:77-88.

17 Hsu SM, Jaffe ES. Leu M1 and peanut agglutinin stain the neoplastic cells of Hodgkin's disease. Am J Clin Pathol 1984;82:29-32.

18 Pinkus GS, Thomas P, Said JW. Leu M1-a marker for Sternberg Reed cells in Hodgkin's disease. An immunoperoxidase study of paraffin embedded tissues. Am J Pathol 1985;119:244-52.
19 Wieczorek R, Burke JS, Knowles DM. Leu M1 antigen expression in T cell neoplasia. Am J Pathol 1985;121:374-80.

20 Sheibani K, Battifora H, Burke JS, Rappaport H. Leu M1 antigen in human neoplasms. An immunohistological study of 400 cases. Am J Surg Pathol 1986;10:227-36.

21 Hyder DM, Schnitzer B. Utility of Leu M1 monoclonal antibody in the differential diagnosis of Hodgkin's disease. Arch Pathol Lab Med 1986;110:416-9.

22 Kadin M, Nasu K, Sako D, Said J, Vonderheid E. Lymphomatoid papulosis. A cutaneous proliferation of activated helper T cells expressing Hodgkin's disease related antigens. Am J Pathol 1985;119:315-25.

23 Galen RS. Application of the predictive value model in the analysis of test effectiveness. Clin Lab Med 1982;2:685-99.

24 Griner PF. Principles of test selection and use. Ann Intern Med 1981;94:557-92.

25 Sox HC. Probability theory in the use of diagnostic tests. An introduction to the critical study of the literature. Ann Intern Med 1986;104:60-6.

26 Pauker SG, Kassirer JP. Decision analysis. $N$ Engl $J$ Med 1987;316:250-8.

27 Ransohoff DF, Feinstein AR. Problems of spectrum and bias in evaluating the efficacy of diagnostic tests. $N$ Engl J Med 1978;299:926-30.

28 Ingram D, Bloch R. Formal approaches to the analysis of clinical decisions. In: Ingram D, Bloch R, eds. Mathematical models in medicine. Part I Statistical and analytical techniques. Chichester: John Wiley and Sons Ltd, 1984:119-59.

29 Berman D, Forrester JS, Morris D, Swan HJC. The declining specificity of exercise radionuclide ventriculography. $N$ Engl J Med 1983;309:518-22.

30 Norton AJ, Isaacson PG. Granulocyte and HLA-D region specific monoclonal antibodies in the diagnosis of Hodgkin's disease. J Clin Pathol 1985;38:1241-6.

31 Pinkus GS, Said JW. Hodgkin's disease, lymphocyte predominant type, nodular. A distinct entity. Am $J$ Pathol 1985;118:1-6.

32 Frierson HF, Innes DJ. Sensitivity of anti-Leu M1 as a marker of Hodgkin's disease. Arch Pathol Lab Med 1985;109:1024-8.

33 Hsu SM, Yang K, Jaffe ES. Phenotypic expression of Hodgkin's and Reed-Sternberg cells in Hodgkin's disease. Am J Pathol 1985;118:209-17.

34 Forni M, Hofman FM, Parker JW, Lukes RJ, Taylor CR. B and T lymphocytes in Hodgkin's disease. An immunohistochemical study utilizing heterologous and monoclonal antibodies. Cancer 1985;55:728-37.

35 Dorfman RF, Gatter KC, Pulford KAF, Mason DY. An evaluation of the utility of anti-granulocyte and anti-leucocyte monoclonal antibodies in the diagnosis of Hodgkin's disease. Am J Pathol 1986;55:728-37.

36 Kornstein MJ, Bonner H, Gee B, Cohen R, Brooks JJ. Leu M1 and $\mathrm{S} 100$ in Hodgkin's disease and non Hodgkin's lymphomas. Am J Cardiol Pathol 1986;85:433-7.

37 Jack AS, Cunningham D, Soukop M, Liddle CN, Lee FD. Use of Leu M1 and anti-epithelial membrane antigen monoclonal antibodies for diagnosing Hodgkin's disease. J Clin Pathol 1986;39:267-70.

38 Swerdlow SH, Wright SA. The spectrum of Leu M1 staining in lymphoid and hematopoietic proliferations. Am J Clin Pathol 1986;85:283-8.

39 Stein H, Hansmann ML, Lennert K, Brandtzaeg P, Gatter KC, Mason DY. Reed Sternberg and Hodgkin's cells in lymphocyte predominant Hodgkin's disease of nodular subtype contain J chain. Am J Clin Pathol 1986;86:292-7.

40 Strauchen JA, Dimitriu-Bona A. Immunopathology of Hodgkin's disease. Characterisation of Reed-Sternberg cells with monoclonal antibodies. Am J Pathol 1986;123:293-300.

41 Myskow MW, Krajewski AS. Immunoreactivity of Reed Sternberg cells in paraffin and frozen section. J Clin Pathol 1986:39:1043-5. 
42 Meis JM, Osborne BM, Butler JJ. A comparative marker study of large cell lymphoma, Hodgkin's disease and true histiocytic lymphoma in paraffin embedded tissue. Am J Clin Pathol 1986;86:591-9.

43 Norton AJ, Isaacson PG. An immunocytochemical study of $t$ cell lymphomas using monoclonal and polycolonal antibodies effective in routinely fixed wax embedded tissues. Histopathology 1986;10:1243-60.

44 Greaves MF, Janossy G, Peto J, Kay H. Immunologically defined subclasses of acute lymphoblastic leukaemia in children: their relationship to presentation features and prognosis. $\mathrm{Br} J \mathrm{Hae}$ matol 1981;48:179-97.

45 Stein H, Mason DY, Gerdes J, etal. The expression of the Hodgkin's disease associated antigen $\mathrm{Kil}$ in reactive and neoplastic tissue: evidence that Reed Sternberg cells and histiocytic malignancies are derived from activated lymphoid cells. Blood 1985;66:848-58.

46 Pinkus GS, Said JW. Leu M1 immunoreactivity in nonhematopoietic neoplasms and myeloproliferative disorders. An immunoperoxidase study of paraffin sections. Am J Clin Pathol 1986;85:278-82.

47 Vernon SE, Morgan TW. Immunoglobulin light chain staining of lymph node biopsies: An interlaboratory comparison. Ann Clin Lab Sci 1981;11:525-9.

48 Grint PCA, Ronalds CJ, Kangro HO, et al. Screening tests for antibiotics to cytomegalovirus: an evaluation of five commercial products. J Clin Pathol 1985;38:1059-64.

49 Gatter KC, Abdulaziz Z, Beverley PCL, et al. Use of monoclonal antibodies for the histopathological diagnosis of malignancy. $J$ Clin Pathol 1982;35:1253-67.

50 Gatter KC, Ralfkiaer E, Skinner J. et al. An immunocytochemical study of malignant melanoma and its differential diagnosis from other malignant tumours. J Clin Pathol 1985;38:1353-7.

51 Bosq J, Gatter KC, Michaeu C, Mason DY. Role of immunohistochemistry in the diagnosis of nasopharyngeal carcinoma. J Clin Pathol 1985;38:845-8.

52 Coakham HB, Garson JA, Allen PM, Harper EI, Brownell B, Kempshead JT, Lane EB. Immunohistological diagnosis of central nervous system tumours using a monoclonal antibody panel. J Clin Pathol 1985;38:165-73.

53 Falini B, Pulford K, Erber W, et al. Use of a panel of monoclonal antibodies for the diagnosis of hairy cell leukaemia. Histopathology 1986;10:671-89.

54 Sloane JP, Ormerod MG. Distribution of epithelial membrane antigen in normal and neoplastic tissues and its value in diagnostic tumour pathology. Cancer 1981;47:1786-95.

55 Leader M, Collins M, Patel J, Henry K. Staining for factor VIII related antigen and Ulex europeus agglutinin I (UEA-I) in 230 tumours. An assessment of their specificity for angiosarcoma and Kaposi's saicoma. Histopathology 1986;10:1153-62.

56 Leader M, Patel J, Makin CA, Henry K. An analysis of the sensitivity and specificity of the cytokeratin marker CAM 5.2 for epithelial tumours. Results of a study of 203 sarcomas, 50 carcinomas and 28 malignant melanomas. Histopathology 1986;10:1315-24.

57 Silcocks PB, Herbert A, Wright DH. Evaluation of PAS-diastase and carcinoembryonic antigen staining in the differential diagnosis of malignant mesothelioma and papillary serous carcinoma of the ovary. $J$ Pathol 1986;149:133-41.

58 Battifora H, Kopinski MI. Distinction of mesothelioma from adenocarcinoma. An immunohistochemical approach. Cancer 1985;55:1679-85.

59 Minkowitz S, Moskowitz R, Khafif RA, Alderete MN. "TruCut" needle biopsy of the breast. An analysis of its specificity and sensitivity. Cancer 1986;57:320-3.

60 Warnke RA, Rouse RV. Limitations encountered in the application of tissue section immunodiagnosis to the study of lymphomas and related conditions. Hum Pathol 1985;16:326-31.

61 Schwartz WB, Wolfe HJ, Pauker SG. Pathology and probabilities. A new approach to interpreting and reporting biopsies. N Engl J Med 1981;305:917-23.

Requests for reprints to: Dr PA Hall, ICRF Research Fellow, Department of Histopathology, St Bartholomew's Hospital, London EClA 7BE, England. 